\title{
Vocal Cord Paralysis and Hypercapnic Respiratory Failure in a Patient with Familial Amyloidotic Polyneuropathy
}

\author{
Aylin Pıhtılı ${ }^{1}$, Züleyha Bingol ${ }^{2}$, Hacer Durmuş ${ }^{3}$, Yeşim Parman ${ }^{3}$ and Esen Kıyan ${ }^{2}$
}

\begin{abstract}
We herein report a patient case with familial amyloidotic polyneuropathy (FAP) who presented with vocal cord paralysis (VCP). A 60-year-old man with FAP (Gly89Gln) presented with hoarseness and snoring for the previous two years. A chest X-ray demonstrated cardiomegaly and bilateral diaphragmatic elevation. The findings of a restrictive pattern on spirometry and daytime hypercapnia were consistent with respiratory muscle weakness related to neuropathy [forced expiratory volume $\left(\mathrm{FEV}_{1}\right)$ : $38 \%$, forced vital capacity (FVC): 39\%, $\mathrm{FEV}_{1} / \mathrm{FVC}$ : 77, partial pressure of arterial oxygen $\left(\mathrm{PaO}_{2}\right): 80 \mathrm{mmHg}$, partial pressure of carbon dioxide in arterial blood $\left(\mathrm{PaCO}_{2}\right): 52 \mathrm{mmHg}$ ]. An ear-nose-throat examination showed VCP. Polysomnography revealed severe obstructive sleep apnea (OSA). FAP may cause OSA by VCP and hypercapnic respiratory failure by respiratory muscle weakness. Therefore, an ear-nose-throat examination, spirometry, arterial blood gases analysis and polysomnography are important for these patients.
\end{abstract}

Key words: familial amyloidotic polyneuropathy, hypercapnia, respiratory muscle weakness, obstructive sleep apnea, vocal cord paralysis

(Intern Med 55: 1783-1786, 2016)

(DOI: 10.2169/internalmedicine.55.5564)

\section{Introduction}

Transthyretin (TTR) is a major amyloidogenic protein that is predominately synthesized in the liver. It causes two types of amyloidotic disease: hereditary systemic amyloidosis, which is induced by the mutated TTR gene, and senile systemic amyloidosis (SSA), which is an aging-related sporadic systemic amyloidosis that is induced by wild-type TTR $(1,2)$. Amyloidosis induced by TTR mutations can be classified into several phenotypes including peripheral neuropathy dominant type, commonly referred to as familial amyloidotic polyneuropathy (FAP); cardiomyopathy dominant type, also known as familial amyloidotic cardiomyopathy; vitreous opacity dominant type, and leptomeningeal amyloidosis dominant type, which causes central nervous symptoms (3). We herein report a case of TTR-related familial amyloidotic polyneuropathy (TTR-FAP) presenting with hoarseness, snoring, awakening with the feeling of drowning, morning headache, daytime sleepiness and dyspnea in the supine position.

\section{Case Report}

A 60-year-old man was admitted to our clinic with hoarseness, snoring, morning headache, awakening with the feeling of drowning, daytime sleepiness and dyspnea in the supine position. He smoked a few cigarettes per day for 10 years. At 45 years of age, he had been diagnosed with familial Mediterranean fever (FMF) and treatment with colchicum was started. However, the patient was negative for a $M E F V$ gene mutation analysis. The patient did not benefit from colchicum treatment. Additionally, there were no signs of FMF during the follow-up and colchicum was subsequently stopped. Symptoms of muscular weakness, difficulty in walking and bilateral carpal tunnel syndrome commenced at 49 years of age. A neurologic examination at this time revealed hypophonia, distal and lower limb prominent weakness of limbs, abolished deep tendon reflexes, stockingglove type hypoesthesia, and decreased vibration sensation.

${ }^{1}$ Haydarpaşa Numune Training and Research Hospital, Turkey, ${ }^{2}$ Department of Pulmonary Medicine, Istanbul University, Istanbul Faculty of Medicine, Turkey and ${ }^{3}$ Department of Neurology, Istanbul University, Istanbul Faculty of Medicine, Turkey

Received for publication April 11, 2015; Accepted for publication October 4, 2015

Correspondence to Dr. Esen Kiyan, kiyanesen@gmail.com 


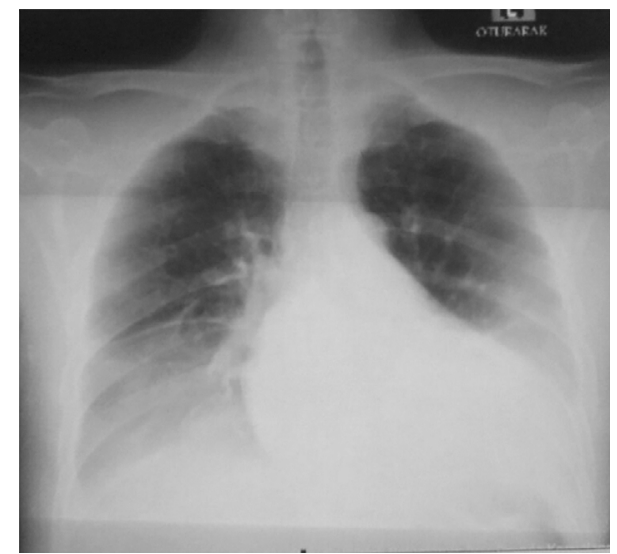

Figure 1. Chest $\mathrm{X}$ ray; There was cardiomegaly and bilaterally elevated diaphragms and there was no parenchymal pathology.

A diagnosis of FAP with Glu89Gln type TTR mutation was made by a nerve biopsy and genetic testing at 54 years of age. Electromyography findings were compatible with sensory-motor axonal polyneuropathy. Amyloid depositions were found in a sural nerve biopsy. Genetic testing revealed Glu89Gln mutation in the TTR gene. Family screening led to the diagnosis of FAP in the patient's mother, uncle, sister, aunt and cousin. At 55 years of age, the patient was bedridden due to weakness and orthostatism (Stage III TTR-FAP). Tafamidis $(20 \mathrm{mg})$ therapy was commenced at 57 years of age. At 59 years of age, hoarseness, snoring, awakening with the feeling of drowning and dyspnea in the supine position were noted. The patient was admitted to our clinic with worsening symptoms.

A physical examination at this admission revealed a blood pressure of $110 / 80 \mathrm{mmHg}$, heart rate of $60 /$ arrhythmic, respiratory rate of $20 / \mathrm{min}$, and body mass index of $23 \mathrm{~kg} / \mathrm{m}^{2}$. Respiratory sounds were normal. S2 was loud at the pulmonary area. The patient demonstrated muscular atrophy of the lower extremities and pretibial edema. The complete blood count was normal. A biochemical analysis was normal other than hypoalbuminemia (albumin: $3 \mathrm{mg} / \mathrm{dL}$ ). The prothrombin time was normal. The patient exhibited cardiomegaly and bilaterally elevated diaphragms on a chest X-ray without parenchymal pathology (Fig. 1). Spirometry demonstrated a severe restrictive pattern [forced expiratory volume $\left(\mathrm{FEV}_{1}\right)$ : $38 \%$, forced vital capacity (FVC): 39\%, $\mathrm{FEV}_{1} / \mathrm{FVC}$ : 77] (Fig. 2). Spirometry performed five years previously was noted as being normal (FVC: $105 \%$ and $\mathrm{FEV}_{1}$ : $104 \%$ ). A daytime arterial blood gases (ABG) analysis at room air revealed hypercapnia [partial pressure of arterial oxygen $\left(\mathrm{PaO}_{2}\right): 80 \mathrm{mmHg}$, partial pressure of carbon dioxide in arterial blood $\left(\mathrm{PaCO}_{2}\right): 52 \mathrm{mmHg}, \mathrm{pH}: 7.42, \mathrm{HCO}_{3}: 27 \mathrm{mmHg}$, $\mathrm{SaO}_{2}: 96.2 \%$ ]. The restrictive pattern on spirometry and daytime hypercapnia were consistent with respiratory muscle weakness related to neuropathy. Atrial fibrillation was noted on Holter monitoring. Echocardiography revealed ejection fraction (EF) of 30\%, systolic pulmonary arterial pressure

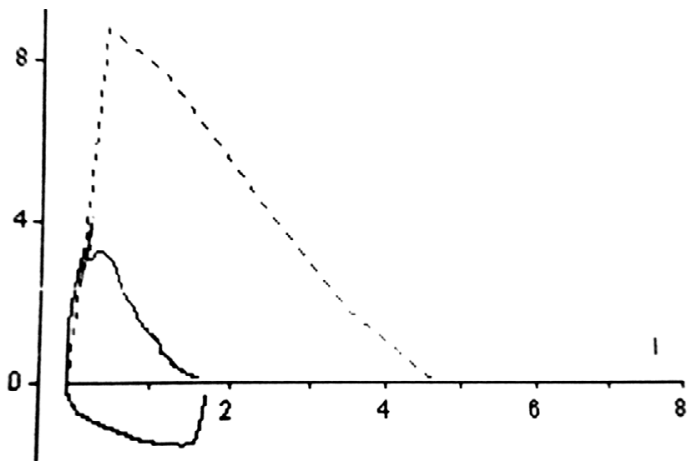

Figure 2. Serious restrictive pattern and plateau on inspiratory phase concordant with extrathoracic airway obstruction on spirometry.

(PAPs) of $55 \mathrm{mmHg}$ and minimal pericardial effusion. Both atria were enlarged and the left ventricular wall was diffusely hypertrophic, particularly at the septum with a granular and hyperechogenic appearance. These findings were compatible with cardiac amyloidosis. An eye examination was normal. Abdominal, renal, and pelvic ultrasonography were normal. An ear-nose-throat examination for hoarseness demonstrated bilateral vocal cord paralysis (VCP) that did not require tracheostomy. Polysomnography demonstrated an apnea-hypopnea index of $35 / \mathrm{h}$, oxygen desaturation index of $30 / \mathrm{h}$, average saturation of $93 \%$, minimum saturation of $52 \%$, time of saturation $<90 \%$ of $14 \%$ (Fig. 3). The ABG analysis immediately on awakening showed $\mathrm{PaO}_{2}: 70$ $\mathrm{mmHg}, \mathrm{PaCO}_{2}: 57 \mathrm{mmHg}, \mathrm{pH}: 7.36$ and $\mathrm{SaO}_{2}: 94 \%$. Bilevel positive airway pressure (BIPAP) titration was performed due to severe obstructive sleep apnea (OSA) and hypercapnia. The patient's respiratory problems improved with BIPAP 15/9 $\mathrm{cmH}_{2} \mathrm{O}$ and the subsequent $\mathrm{ABG}$ analysis showed $\mathrm{PaO}_{2}: 76 \mathrm{mmHg}, \mathrm{PaCO}_{2}: 47 \mathrm{mmHg}, \mathrm{pH}: 7.42$ and $\mathrm{SaO}_{2}: 96 \%$.

\section{Discussion}

In our patient who presented with hoarseness, snoring, awakening with a feeling of drowning, morning headache, daytime sleepiness and dyspnea in the supine position and was diagnosed with TTR-FAP with the Glu89Gln mutation in TTR, we detected hypercapnic respiratory failure secondary to respiratory muscle weakness and $\mathrm{VCP}$ with associated severe OSA.

FAP is more common in Sweden, Japan, Brazil, Majorca and Ireland. The prevalence of different mutations varies according to ethnicity and geographical region (4). People living elsewhere who have FAP often have ancestors from these regions. The presenting signs and symptoms depend on the TTR gene variant present and the organ(s) involved. The most common sites of deposition involve the heart, peripheral nervous system, and gastrointestinal system. Currently, approximately 100 TTR variants are known, with varying geographic distributions, degrees of amyloidogenic- 


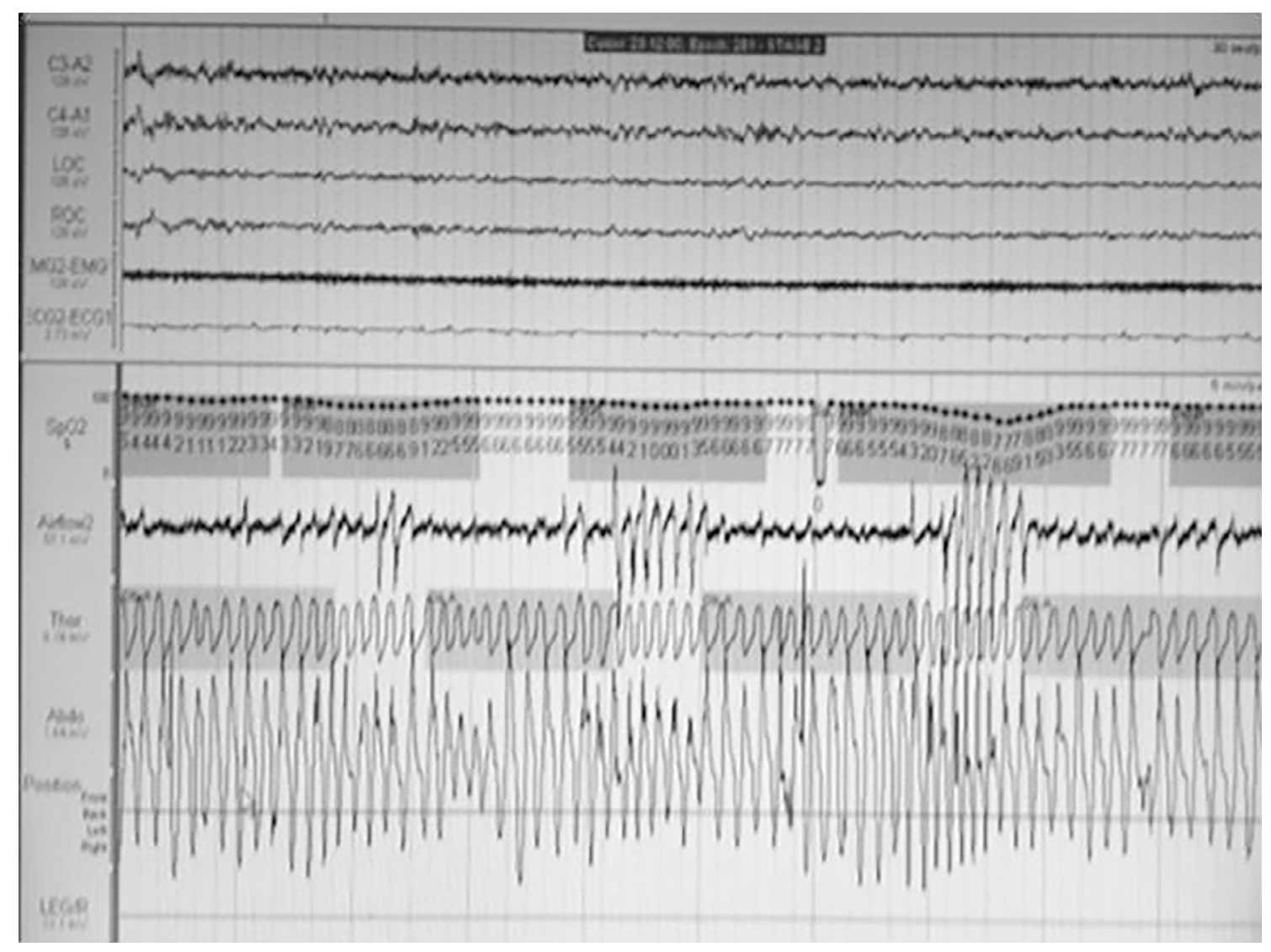

Figure 3. Hypopnea and obstructive apneas with associated desaturations on polysomnography.

ity, and organ predisposition. The age at symptom onset, pattern of organ involvement, and disease course vary, however, most mutations are associated with cardiac and/or nerve involvement. The gastrointestinal tract, vitreous, lungs, and carpal ligament are also frequently affected (5). Focal accumulation of amyloid is rare except in carpal tunnel. Cranial nerve involvement in TTR-FAP is also unusual $(6,7)$. Only a few rare cases with cranial nerve XII and vocal cord involvement have been reported. Vocal cord involvement is independent of the disease severity and may be a presenting symptom accompanying the polyneuropathy findings (6). The prognosis is highly variable on an individual basis (8). Other unknown factors also play a role in $T T R$ amyloid formation, as the clinical manifestations of the disease vary widely among people carrying the same TTR variant.

The most common type of FAP is caused by the Val30Met variant of TTR. This mutation affects approximately 1 in 500 people in some regions of Northern Portugal (9). Patients with this mutation typically have sensorimotor polyneuropathy, autonomic dysfunction, heart and kidney failure, and gastrointestinal tract disorders and tend to die within 10 years of the disease onset (10-12). Lower cranial nerves are affected in the advanced stages (13). The clinical disease generally manifests as a peripheral sensory, motor and autonomic neuropathy starting in the 3rd or 4th decade of life (14). The disease onset is earlier in men than in women. The other amyloid-associated TTR variants ap- pear to be less common, although no concrete data are available regarding the population prevalence. Our patient had the Glu89Gln TTR variant. In these patients, the clinical presentation has been reported as polyneuropathy, cardiomyopathy and carpal tunnel syndrome (9-15). Our patient also had a history of carpal tunnel syndrome, difficulty walking and muscular weakness followed by paraplegia before presenting to our clinic.

Few cases have reported vocal cord involvement in amyloidosis $(7,16)$. However, none of the previous cases had VCP associated with FAP. One of these cases was diagnosed with FAP with vocal cord involvement, but not VCP (7). That case presented with hoarseness of the voice that was attributed to amyloid deposition in the vocal cords (7). The other case did not have a diagnosis of FAP (16). In this second case, there was a compression of the laryngeal nerve by mediastinal lymphadenopathy due to amyloidosis (16). Our patient had no mediastinal pathology. Additionally, fiberoptic laryngoscopy revealed no macroscopic finding of amyloid accumulation on the vocal cords or larynx. The patient underwent a sural nerve biopsy which showed amyloid deposition. Although we did not perform a laryngeal biopsy, we speculated that VCP in our patient could be attributed to recurrent amyloid deposition in the laryngeal nerve associated with TTR-FAP. There was no other neurologic cause of VCP in our patient. The flow-volume curve was suggestive of upper respiratory tract obstruction with spirometry. VCP is an important risk factor for OSA. Our patient exhibited 
the characteristic complaints of OSA and severe OSA was detected on polysomnography.

Amyloid deposition in the pulmonary parenchyma is rare in FAP. Cases with pulmonary involvement typically present with hemoptysis and dyspnea (17-19). In the pertinent literature, a case report presented the case of transthyretin amyloidosis and parenchymal interstitial involvement (18). This case admitted with dyspnea showed signs of alveolar and interstitial involvement with thickening of the septal lines on thoracic high-resolution computed tomography. A pathological assessment of lung specimens revealed nodular deposits of amyloid in the bronchial walls and lung parenchyma. Congo red staining was positive (18). Pulmonary amyloidosis was determined in 19 autopsied lung samples from patients with FAP amyloidogenic TTR (ATTR) V30M (20). Amyloid deposition was also observed around the walls of the bronchi/bronchioles, pulmonary arteries, and pulmonary veins, while no amyloid deposits could be found around the lymphatics. In addition, amyloid deposition in the alveolar regions was a characteristic finding in aged patients with FAP TTR V30M (20). Our patient did not have respiratory symptoms, such as a cough, sputum, or hemoptysis, and there was no parenchymal pathology in his chest X-ray. Therefore, we did not suspect interstitial pneumonia in our patient.

Neuropathy in FAP may cause respiratory muscle weakness. A restrictive pattern on spirometry with reduced maximum expiratory and inspiratory pressures indicates that the neuropathy involves not only the extremities, but also the respiratory muscles (21). In our patient, the spirometric measurements plus daytime hypercapnia and increased $\mathrm{PaCO}_{2}$ on awakening were associated with respiratory muscle involvement. Spirometry was performed in the supine position because the patient was unable to sit. Therefore, because we could not compare supine and sitting FVC, we are unable to comment on the diaphragm dysfunction secondary to neuropathy.

Cardiac involvement is reported in approximately $80 \%$ of FAP cases and some cases have an exclusive or predominant cardiac phenotype. It has been reported that Glu89Gln is associated with a more severe cardiomyopathy compared to Val30Met. Glu89Gln is independently associated with a higher risk of major cardiovascular events among cardiomyopathy patients $(3,4)$. Our patient demonstrated atrial fibrillation on Holter monitoring. EF was $30 \%$, PAPs was $55 \mathrm{mmHg}$ and mild pericardial effusion was detected on echocardiography. The findings of biatrial enlargement, diffuse thickening of the left ventricular wall especially at the septum and granular-hyperechogenic appearance were compatible with cardiac amyloidosis.

In conclusion, FAP caused by the Glu89Gln variant of TTR may lead to OSA due to vocal cord paralysis and hypercapnic respiratory failure due to respiratory muscle weak- ness. Therefore, patients with FAP should routinely undergo vocal cord examinations and spirometry, ABG analysis, and even supine vs. sitting spirometry. When necessary, polysomnography should also be performed.

The authors state that they have no Conflict of Interest (COI).

\section{References}

1. Planté-Bordeneuve V, Said G. Familial amyloid polyneuropathy. Lancet Neurol 10: 1086-1097, 2011.

2. Ando Y, Nakamura M, Araki S. Transthyretin-related familial amyloidotic polyneuropathy. Arch Neurol 62: 1057-1062, 2005.

3. Ueda M, Ando Y. Recent advances in transthyretin amyloidosis therapy. Transl Neurodegener 3: 19, 2014.

4. Rapezzi C, Perugini E, Salvi F, et al. Phenotypic and genotypic heterogeneity in transthyretin-related cardiac amyloidosis: towards tailoring of therapeutic strategies? Amyloid 13: 143-153, 2006.

5. Connors LH, Lim A, Prokaeva T, Roskens VA, Costello CE. Tabulation of human transthyretin (TTR) variants. Amyloid 10: 160$184,2003$.

6. Plante-Bordeneuve V, Ferreira A, Lalu T, et al. Diagnostic pitfalls in sporadic transthyretin familal amyloid polyneuropathy (TTRFAP). X Neurology 69: 693-698, 2007.

7. Uttam AK, Prasad K, Sharma MC, Sigamani E. Familial amyloid neuropathy: Unusual etiology in clinical practice. Neurol India 60: 430-431, 2012

8. Varga J, Wohlgethan JR. The clinical and biochemical spectrum of hereditary amyloidosis. Semin Arthritis Rheum 18: 14-28, 1988.

9. Almeida MR, Ferlini A, Forabosco A, et al. Two Transthyretin variants (TTR Ala-49 and TTR Gln-89) in two Sicilian kindreds with hereditary amyloidosis. Hum Mutat 1: 211-215, 1992.

10. Suhr OB, Svendsen IH, Andersson R, Danielsson A, Holmgren G, Ranløv PJ. Hereditary transthyretin amyloidosis from a Scandinavian perspective. J Intern Med 254: 225-235, 2003.

11. Shimizu H, Ishikawa K, Kobayashi H, et al. Familial amyloidotic polyneuropathy with a transthyretin variant (Val30-->Leu). No To Shinkei (Brain and Nerve) 48: 175-178, 1996 (in Japanese).

12. Conceição I, De Carvalho M. Clinical variability in type I familial amyloid polyneuropathy (Val30Met): comparison between lateand early-onset cases in Portugal. Muscle Nerve 35: 116-118, 2007.

13. Ikeda S, Hanyu N, Hongo M, et al. Hereditary generalized amyloidosis with polyneuropathy. Clinicopathological study of 65 Japanese patients. Brain 110: 315-337, 1987.

14. Lobato L. Portuguese-type amyloidosis (transthyretin amyloidosis, ATTR V30M). J Nephrol 16: 438-442, 2003.

15. Skare JC, Saraiva MJ, Alves IL, et al. A new mutation causing familial amyloidotic polyneuropathy. Biochem Biophys Res Commun 164: 1240-1246, 1989.

16. Conaghan P, Chung D, Vaughan R. Recurrent laryngeal nerve palsy associated with mediastinal amyloidosis. Thorax 55: 436437, 2000.

17. Diaz Lobato S, Guerrero E, Gonzalez P, Crespo M, Esteban R, Vilasante C. Pulmonary involvement in familial amyloid polyneuropathy type I. Rev Clin Esp 189: 335-337, 1991.

18. Kruczak K, Duplaga M, Sanak M, et al. Transthyretin amyloidosis with pulmonary involvement in a patient with monoclonal gammapathy. Pneumonol Alergol Pol 81: 537-541, 2013.

19. Morita M, Hongo M, Koizumi T, et al. Familial amyloid polyneuropathy presenting as recurrent hemoptysis and hemosputum: detection of amyloid deposition of the lung by transbronchial lung biopsy. Nihon Naika Gakkai Zasshi (J Jpn Soc Int Med) 77: 14351439, 1988 (in Japanese).

20. Ueda M, Ando Y, Haraoka $K$, et al. Aging and transthyretinrelated amyloidosis: pathologic examinations in pulmonary amyloidosis. Amyloid 13: 24-30, 2006.

21. Olofsson BO. Pulmonary function in familial amyloidosis with polyneuropathy. Acta Med Scand 209: 379-384, 1981.

(C) 2016 The Japanese Society of Internal Medicine http://www.naika.or.jp/imonline/index.html 